\title{
Suppressive Effect of Curcumin on Trichloroethylene-induced Oxidative Stress
}

\author{
Satoshi Watanabe and Tetsuya FukuI \\ Department of Health Chemistry, Faculty of Pharmaceutical Sciences, Hoshi University, \\ 4-41, Ebara 2-chome, Shinagawa-ku, Tokyo 142-8501, Japan
}

(Received February 28, 2000)

\begin{abstract}
Summary In vivo antioxidative effects of curcumin were investigated using a trichloroethylene (TCE)-induced oxidative stress model in mouse liver. Increases in the contents of peroxisome and thiobarbituric acid reactive substances (TBARS) and decreases in GSH content of mouse liver by the TCE administration were suppressed by the pre-administration of curcumin. TCE-induced changes in the activities of antioxidative enzyme, such as $\mathrm{Cu} / \mathrm{Zn}-\mathrm{SOD}$, catalase, glutathione reductase, glutathione peroxidase (GPx) and D-glucose-6phosphate dehydrogenase (G6PD), were also diminished by curcumin. These results indicate that curcumin significantly suppresses TCE-induced oxidative stress by scavenging various free radicals, and its antioxidative activity seems to be derived from its suppressive effects on the increase in peroxisome content and decrease in GPx and G6PD activities.
\end{abstract}

Key Words curcumin, antioxidant, trichloroethylene, reactive oxygen species, oxidative stress

Recently, there have been several reports on the correlation between certain diseases and oxidative stress caused by reactive oxygen species (ROS), such as superoxide anion radical, hydrogen peroxide and hydroxyl radicals (1-3). For example, ROS generated by macrophages activated through the defense mechanisms of mammals is known to act as a mediator of various inflammatory diseases (4). Although, ROS is inevitably generated by neutrophils during phagocytosis to resist bacteria and other xenobiotics (5), if it is generated in an uncontrolled manner, certain cellular components, such as lipids, proteins and nucleic acids, are easily and rapidly oxidized by excessive ROS, and such reactions would lead to an increase in lipid peroxide level, alterations of protein functions, and DNA damage $(6,7)$. In fact, abnormal production of ROS induced by chemicals or diseases, such as adriamycin or hyperlipidemia, respectively, brings about certain inflammatory diseases such as arthritis $(8)$.

Thus, there have been several attempts to use antioxidants as preventive agents for oxidative stress. Free radical scavengers and active oxygen modulators, such as vitamin $\mathrm{E}$ and superoxide dismutase (SOD), are expected to prevent ROS-induced oxidative stress $(9,10)$.

Curcumin, isolated from turmeric (Curcuma longa), is known to have several pharmacological properties, such as anti-tumor and anti-inflammatory activities $(11,12)$. It is a natural plant antioxidant and has an anti-mutagenic property (13). The American National Cancer Institute has evaluated curcumin as a chemopreventive agent since the phorbol ester-induced tumor promotion in mouse skin was found to be prevented sig-

E-mail : satoshi@hoshi.ac.jp nificantly by curcumin (14). Curcumin is also regarded as an anti-inflammatory agent since it is an inhibitor of arachidonic acid metabolism $(15,16)$. Furthermore, a recent study has indicated that curcumin is a candidate for an antiviral agent against human immunodeficiency virus (17). However, the preventive effect of curcumin and its role on oxidative stress in vivo have not been clarified yet, as has other natural antioxidants such as thymol (18) and gingerol (19).

In this study, we examined the effect of curcumin on trichloroethylene (TCE)-induced oxidative stress. TCE is a well-known environmental pollutant and induces both oxidative stress and peroxisome proliferation in mouse liver (20). The present paper describes that both TCE-induced changes of oxidative stress parameters and increase in peroxisome content in mouse liver were significantly suppressed by the pre-administration of curcumin.

\section{MATERIALS AND METHODS}

Chemicals. Glutathione reductase from bakers yeast (EC 1.6.4.2), xanthine oxidase from milk (EC 1.1.3.22), reduced and oxidized glutathione, xanthine, and bovine serum albumin were purchased from Sigma Chemical Co. (St. Louis, MO, USA). 1,1,3,3-Tetraethoxypropane was obtained from Aldrich Chemical Co. (Milwaukee, WI, USA). Other chemicals of the highest grade of purity were purchased commercially.

Animals. Male ddY mice (5-wk-old), obtained from Tokyo Experimental Animal Supply Co., Tokyo, were used. They were preliminarily bred for $1 \mathrm{wk}$ on normal diet with free feeding and used for the experiment at 6 wk of age. Curcumin dissolved in $0.1 \mathrm{~mL}$ of DMSO was intraperitoneally applied to mice at $10 \mu \mathrm{mol} / \mathrm{kg}$ as the 
Table 1. Effects of TCE and curcumin on body weight and relative liver weight of mice.

\begin{tabular}{ccccc}
\hline Group & TCE & Curcumin $(\mu \mathrm{mol} / \mathrm{kg})$ & Body weight $(\mathrm{g})$ & Relative liver weight $^{\#}$ \\
\hline I & - & - & $34.6 \pm 2.3^{\mathrm{a}}$ & $7.41 \pm 0.60^{\mathrm{a}}$ \\
II & + & - & $35.1 \pm 1.1^{\mathrm{a}}$ & $7.27 \pm 0.35^{\mathrm{ab}}$ \\
III & + & 10 & $35.9 \pm 3.5^{\mathrm{a}}$ & $7.21 \pm 0.56^{\mathrm{ab}}$ \\
IV & + & 50 & $39.2 \pm 1.5^{\mathrm{b}}$ & $7.23 \pm 0.19^{\mathrm{ab}}$ \\
V & + & 100 & $36.2 \pm 0.9^{\mathrm{ab}}$ & $6.65 \pm 0.46^{\mathrm{b}}$ \\
\hline
\end{tabular}

TCE $(1.2 \mathrm{mmol} / \mathrm{kg})$ was intraperitoneally applied to mice. Group I is control, Group II is TCE control, Group III is low-dose, Group IV is medium-dose and Group V is high-dose curcumin, respectively. Values are means \pm SD $(n=4)$. ${ }^{\text {ab }}$ Values not sharing a common letter are significantly different at $p<0.05$.

\# Liver weight $\times 100$ /body weight.

low dose (Gpoup III), $50 \mu \mathrm{mol} / \mathrm{kg}$ as the medium dose (Group IV) and $100 \mu \mathrm{mol} / \mathrm{kg}$ as the high dose (Group $V$ ). For the control (Group I) and the TCE control (Group II), $0.1 \mathrm{~mL}$ of DMSO without curcumin was used. Twenty-four hours after curcumin administration, $1.2 \mathrm{mmol} / \mathrm{kg}$ of TCE diluted to $0.1 \mathrm{~mL}$ in corn oil (Group II-V) or $0.1 \mathrm{~mL}$ of corn oil without TCE (Group I) was intraperitoneally applied to mice. All mice were fasted for $24 \mathrm{~h}$ after TCE administration and were sacrificed by decapitation. After sufficient phlebotomy, their livers were quickly removed in ice-cold saline. This experimental design was approved by the Animal Experiment Committee of Hoshi University, and all of the mice were cared for in line with the Guidelines Concerning Care and Use of Laboratory Animals.

Fractionation of liver cytosol. A 10\% homogenate of $0.8 \mathrm{~g}$ liver in ice-cold saline was centrifuged at $105,000 \times g$ for $1 \mathrm{~h}$ at $4^{\circ} \mathrm{C}$. A part of the resulting supernatant was used for measurement of antioxidative enzyme activities.

Preparation of peroxisome fraction. The peroxisome fraction was prepared by the method of Leighton et al. (21). Briefly, $20 \%$ homogenate of $1 \mathrm{~g}$ liver in $0.25 \mathrm{~m} \mathrm{su}-$ crose $/ 0.1 \%$ ethanol was centrifuged at $1,000 \times g$ for $10 \mathrm{~min}$ at $4^{\circ} \mathrm{C}$. Then, the supernatant was further centrifuged at $20,000 \times g$ for $15 \mathrm{~min}$. The pellet was resuspended in ice-cold $0.25 \mathrm{M}$ sucrose $/ 0.1 \%$ ethanol and further centrifuged at $20,000 \times g$ for $15 \mathrm{~min}$. This washing procedure was repeated two times. The resulting pellet was suspended in ice-cold $0.25 \mathrm{M}$ sucrose/ $0.1 \%$ ethanol and used for the measurement of peroxisome content.

Measurement of peroxisome content. The peroxisome content was measured as $\mathrm{KCN}$-insensitive palmitoylCoA oxidation activity as described by Zanelli et al. (22).

Measurement of antioxidative enzyme activities. $\mathrm{Cu} /$ Zn-SOD (23), catalase (24), glutathione peroxidase (GPx) (25), glutathione reductase (GR) (26), and D-glucose-6-phosphate dehydrogenase (G6PD) (27) were measured as described elsewhere.

Measurement of TBARS content. The thiobarbituric acid reactive substances (TBARS) content in the liver was measured by the method of Taniguchi and Hara (28). Briefly, $0.2 \mathrm{~g}$ of liver was homogenized in $10 \mathrm{~mL}$ of $0.05 \mathrm{~N} \mathrm{HCl}$. To a $3.0 \mathrm{~mL}$ aliquot of the homogenate,
$1.0 \mathrm{~mL}$ of $0.67 \%$ 2-thiobarbituric acid solution was added, mixed vigorously, and heated in boiling water for $30 \mathrm{~min}$. A sample was then immediately cooled in tap water, $4.0 \mathrm{~mL}$ of $n$-butanol $/$ methanol $(85: 15)$ added, and vigorously mixed for $1 \mathrm{~min}$. After centrifugation at $600 \times g$ for $10 \mathrm{~min}$ at room temperature, the separated organic layer of the sample was collected and dehydrated with anhydrous sodium sulfate. The absorbance of the dehydrated organic layer at $535 \mathrm{~nm}$ was measured using a U-2000 Spectrophotometer (Hitachi Co., Tokyo). 1,1,3,3-Tetraethoxypropane was used for the standard of TBARS.

Measurement of GSH content. The reduced glutathione (GSH) content of liver was measured using HPLC (Hitachi Co., Ltd., Tokyo, Japan) as previously described (29). HPLC conditions were as follows: solvent, $0.1 \mathrm{M}$ sodium phosphate in $1 \%$ phosphoric acid; flow rate, $1.0 \mathrm{~mL} / \mathrm{min}$; column, LiChrosorb RP18-5 (4.6× $150 \mathrm{~mm}$ ); detection, at $217 \mathrm{~nm}$ with a L-4000 UV detector and D-2500 chromatointegrator.

Measurement of protein content. The protein content was determined by the method of Lowry et al. (30) using bovine serum albumin as the standard protein.

Statistics. Data were expressed as the mean \pm SD. One-way ANOVA was used to determine any significant differences $(p<0.05)$ between means. When significant differences were found, Duncan's multiple range test was used to determine the exact nature of the difference.

\section{RESULTS AND DISCUSSION}

Intraperitoneally administrated curcumin is much more active than when administered orally (31). Orally administered curcumin is poorly absorbed from the digestive tract (32), but there is information on the concentration of curcumin in mouse liver after intraperitoneal administration (33). For these reasons, we used intraperitoneal injection in this study in order to clearly confirm the effects of curcumin.

We observed no significant change in body weight or relative liver weight of mice by the administration of $1.2 \mathrm{mmol} / \mathrm{kg}$ TCE (Group II compared to Group I) (Table 1). Pre-administration of a low dose $(10 \mu \mathrm{mol} / \mathrm{kg}$, Group III) of curcumin before TCE administration affected neither body weight nor relative liver weight. However, in the medium-dose group $(50 \mu \mathrm{mol} / \mathrm{kg}$, 


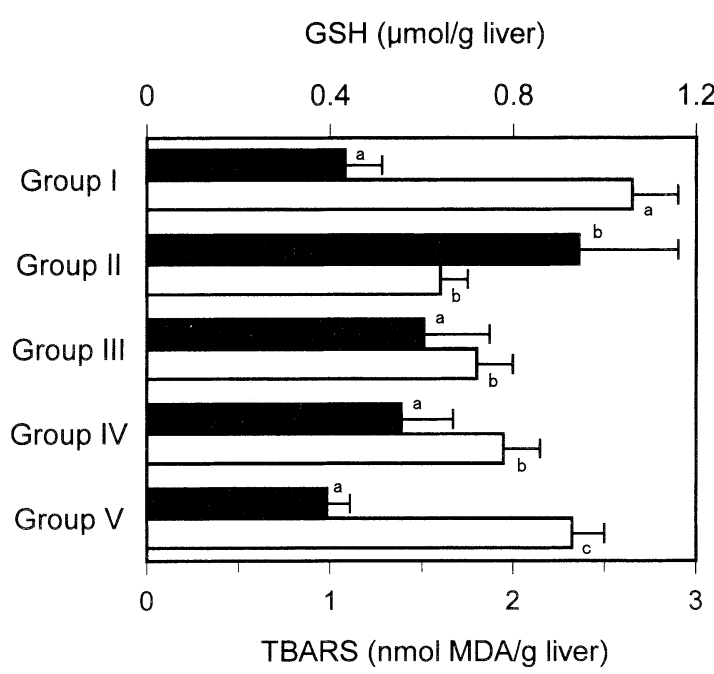

Fig. 1. Suppressive effect of curcumin on TCE-induced changes in both TBARS content and GSH content in the mouse liver. TCE $(1.2 \mathrm{mmol} / \mathrm{kg})$ and curcumin were applied to mice intraperitoneally. Group I is control, Group II is TCE control, Gropu III is low-dose ( $10 \mu \mathrm{mol} / \mathrm{kg}$ of curcumin), Group IV is medium-dose ( $50 \mu \mathrm{mol} / \mathrm{kg}$ of curcumin), and Group $\mathrm{V}$ is high-dose (100 $\mu \mathrm{mol} / \mathrm{kg}$ of curcumin). $\mathbf{\square}$ and $\square$ indicate TBARS content and GSH content, respectively. Values are means \pm SD $(n=4)$. ${ }^{\text {abc }}$ Values not sharing a common letter are significantly different at $p<0.05$.

Group IV), body weight increased significantly, and a significant change in relative liver weight was observed in the high-dose group $(100 \mu \mathrm{mol} / \mathrm{kg}$, Group V) (Table 1); curcumin administration seems to contribute to these changes.

On the other hand, TCE administration significantly increased hepatic TBARS content, and this increase was significantly suppressed by the pre-administration of curcumin in a dose-dependent manner (Fig. 1). Hepatic GSH content was also significantly decreased by TCE administration, and the pre-administration of curcumin significantly suppressed this decrease (Fig. 1). Increase in TBARS content and decrease in GSH content are frequently observed in various mammalian tissues during oxidative stress status, and both are generally used as the parameters of oxidative stress status $(28,34)$. That is, TBARS content is known to increase with the ROS-initiated chain reaction of lipid peroxidation (34), and GSH is reported to decrease in the reaction with various free radicals. Therefore, significant changes in TBARS and GSH contents induced by TCE indicates that TCE caused oxidative stress in the mouse liver. Since curcumin significantly suppressed both TCEinduced changes in a dose-dependent manner, it seems to have not only in vitro antioxidative activity but also in vivo activity.

Peroxisome content was also enhanced significantly by the administration of TCE, and this increase was suppressed significantly by the pre-administration of curcumin (Fig. 2). Since hydrogen peroxide is produced in peroxisome, and it is rapidly degraded to generate hydroxyl radicals in the presence of transition metals (35),

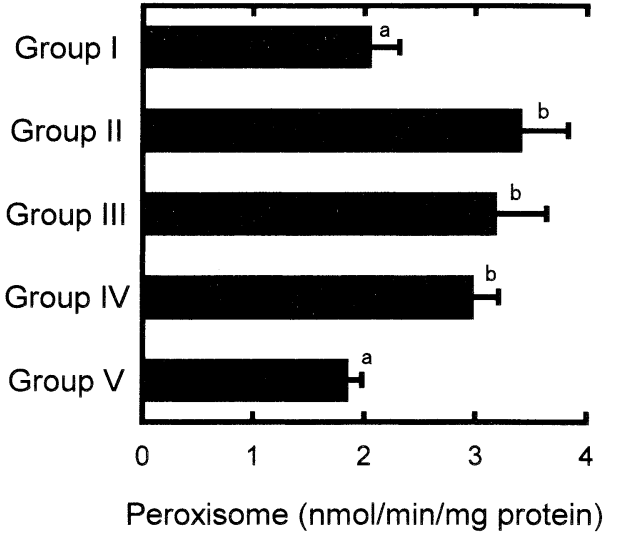

Fig. 2. Suppressive effect of curcumin on TCE-induced increase in peroxisome content in the mouse liver. TCE $(1.2 \mathrm{mmol} / \mathrm{kg})$ and curcumin were applied to mice intraperitoneally. Group I-Group V are the same as in Fig. 1. Values are means \pm SD $(n=4)$. ${ }^{\text {ab }}$ Values not sharing a common letter are significantly different at $p<0.05$.

the increase in peroxisome content seems to be responsible for the induction of hepatic oxidative stress by TCE (Group II). Accordingly, the suppressive effect of curcumin on TCE-induced oxidative stress is likely to be due to the prevention of peroxisome increase by this substance. Since trichloroacetate (TCA), a metabolite of TCE, is suggested to exhibit its peroxisome-proliferative effect through binding to peroxisome proliferator-activated receptor (PPAR) (22), it is possible that curcumin interferes with the signal transduction of TCA.

As shown in Table 2, antioxidative enzyme activities were altered by the administration of $1.2 \mathrm{mmol} / \mathrm{kg}$ TCE. Especially, significant decreases were observed in GPx and G6PD activities. Since GPx catalyzes nonspecific reduction of various peroxides including hydrogen peroxide and lipid peroxides in cells, it is conceivable that the decrease in GPx activity induces the elevation of lipid peroxide level. Similarly, G6PD catalyzes the regeneration of NADPH in redox cycling, and a decrease in G6PD activitiy causes the depression of NADPH. The depression of NADPH would bring about a decrease in the reduction of oxidized glutathione (GSSG) by GR in liver cells. Thus, TCE-induced increase in TBARS content and decrease in GSH content (Fig. 1) are consistent with the changes of these antioxidative enzyme activities. Pre-administration of curcumin significantly suppressed TCE-induced decrease in GPx and G6PD activities in liver cytosol (Table 2), and it seemed to be related to the suppressive effect of curcumin on the TCE-induced changes of hepatic TBARS and GSH contents.

Contrary to GPx and G6PD activities, Cu/Zn-SOD, catalase and GR activities were enhanced by TCE administration (Table 2). These increases in enzyme activities suggest that the TCE-induced oxidative stress status was caused through the increase of superoxide anion radical, hydrogen peroxide and GSSG in liver cells (34, 36). TCE-induced increases of these antioxidative enzyme activities were also significantly suppressed by curcumin pre-administration (Table 2). 
Table 2. Effect of curcumin on the TCE-induced changes of enzyme activities.

\begin{tabular}{|c|c|c|c|c|c|c|c|}
\hline \multirow{2}{*}{ Group } & \multirow{2}{*}{ TCE } & \multirow{2}{*}{ Curcumin $(\mu \mathrm{mol} / \mathrm{kg})$} & $\mathrm{Cu} / \mathrm{Zn}-\mathrm{SOD}$ & Catalase & GPx & GR & G6PD \\
\hline & & & \multicolumn{2}{|c|}{ (units/mg protein) } & \multicolumn{3}{|c|}{ (units $\times 10^{-3} / \mathrm{mg}$ protein) } \\
\hline I & - & - & $8.39 \pm 0.56^{\mathrm{a}}$ & $570 \pm 182^{\mathrm{a}}$ & $290 \pm 42^{\mathrm{a}}$ & $60.8 \pm 4^{\mathrm{ac}}$ & $20.5 \pm 4.3^{\mathrm{a}}$ \\
\hline II & + & - & $15.81 \pm 1.91^{b}$ & $1109 \pm 129^{b}$ & $142 \pm 54^{b}$ & $79.2 \pm 10^{\mathrm{b}}$ & $8.7 \pm 2.3^{b}$ \\
\hline III & + & 10 & $13.02 \pm 2.28^{\mathrm{c}}$ & $922 \pm 93^{b}$ & $180 \pm 26^{b c}$ & $67.6 \pm 9.2^{c}$ & $7.4 \pm 1.2^{b}$ \\
\hline IV & + & 50 & $10.64 \pm 1.95^{\mathrm{ac}}$ & $708 \pm 110^{\mathrm{a}}$ & $188 \pm 30^{\mathrm{bc}}$ & $54.0 \pm 3.2^{\mathrm{a}}$ & $9.4 \pm 0.9^{b c}$ \\
\hline $\mathrm{V}$ & + & 100 & $9.91 \pm 0.98^{\mathrm{a}}$ & $713 \pm 96^{\mathrm{a}}$ & $222 \pm 26^{c}$ & $52.0 \pm 5.2^{\mathrm{a}}$ & $13.9 \pm 4.6^{c}$ \\
\hline
\end{tabular}

TCE (1.2 mmol/kg) was intraperitoneally applied to mice. Group I is control, Group II is TCE control, Group III is low-dose, Group IV is medium-dose and Group V is high-dose curcumin, respectively. Values are means \pm SD $(n=4)$. ${ }^{\text {abc }}$ Values not sharing a common letter are significantly different at $p<0.05$.

TCE has been historically and extensively used as a metal degreaser, extractant, etc., and it is now a common and persistent environmental contaminant found in groundwater. Human exposure to environmental levels of TCE is frequently a health concern primarily because of its carcinogenesis (37). Acute or chronic TCE intake induces increases in lipid peroxide levels and peroxisome contents in mammalian liver cells, and TCE-induced increase in peroxisome content has been suggested to cause hepatic oxidative stress $(20,38)$. TCE is known to be metabolized to TCA and trichloroethanol in liver cells $(20,39)$. A part of TCA is reported to be further metabolized to dichloroacetate (DCA), which is converted to DCA radicals and DCA peroxyl radicals, and these free radicals are suggested to induce oxidative stress (39) and cause certain diseases, such as inflammations and atherosclerosis $(4,40)$. Recently, some antioxidants have been examined for the prevention of several diseases that result from oxidative stress, such as atherosclerosis and hyperlipidemia $(41,42)$. Curcumin is known to rapidly react with hydroxyl radicals and other free radicals, and two phenolic $\mathrm{OH}$ groups in the curcumin structure have been suggested to contribute the antioxidative effect of this compound, such as catechins and flavonoids $(12,13)$. Accordingly, the antioxidative effect of curcumin has been supported to be the result of free radical-scavenging activity (43). However, the in vivo effect of curcumin on the oxidative stress status induced by some chlorinated organic compounds, such as TCE and chloroform, has not yet been clarified, even though daily human intake is indicated to be about $100 \mathrm{mg}$ (31).

According to our results of in vivo experiments, it is likely that the antioxidative effect of curcumin results from not only its radical scavenging ability but also suppressive activity on TCE-induced changes of peroxisome content and antioxidative enzyme activities.

\section{Acknowledgement}

This research was supported in part by the Ministry of Education, Science, Sports and Culture of Japan.

\section{REFERENCES}

1) Adamo AM, Llesuy SF, Pasquini JM, Boveris A. 1989. Brain chemiluminescence and oxidative stress in hyper- thyroid rats. Biochem J 263: 273-277.

2) Mukerji SK, Pimstone NR. 1990. Free radical mechanism of oxidation of uroporphyrinogen in the presence of ferrous iron. Arch Biochem Biophys 281: 177-184.

3) Karayalcin SS, Sturbaum CW, Wachsman JT, Cha JH, Powell DW. 1990. Hydrogen peroxide stimulates rat colonic prostaglandin production and alters electrolyte transport. J Clin Invest 86: 60-68.

4) Masini E, Palmerani B, Gambassi F, Pistelli A, Giannella E, Occupati B, Ciuffi M, Sacchi TB, Mannaioni PF. 1990. Histamine release from rat mast cells induced by metabolic activation of polyunsaturated fatty acids into free radicals. Biochem Pharmacol 39: 879-889.

5) Clark RA. 1990. The human neutrophil respiratory burst oxidase. J Infectious Dis 161: 1140-1147.

6) Hearse DJ. 1977. Reperfusion of the ischemic myocardium. J Mol Cell Cardiol 9: 605-616.

7) Demopoulos HB, Flamm ES, Seligman ML, Pietronigro DD, Tomasula J, DeCrescito V. 1982. Further studies on free-radical pathology in the major central nervous system disorders: effect of very high doses of methylpredonisolone on the functional outcome, morphology, and chemistry of experimental spinal cord impact injury. Can J Physiol Pharmacol 60: 1415-1424.

8) Sakai A, Hirano T, Okazaki R, Okimoto N, Tanaka K, Nakamura T. 1999. Large-dose ascorbic acid administration suppresses the development of arthritis in adjuvant-infected rats. Arch Orthop Trauma Surg 119: 121-126.

9) DeMaio SJ, King SB 3rd, Lembo NJ, Roubin GS, Hearn JA, Bhagavan HN, Sgoutas DS. 1992. Vitamin E supplementation, plasma lipids and incidence of restenosis after percutaneous transluminal coronary angioplasty (PTCA). J Am Coll Nutr 11: 68-73.

10) Obayashi H, Koshi S, Miyauchi Y, Inoue M. 1991. Inhibition of posthemorrhagic transfusion-induced gastric injury by a long-acting superoxide dismutase derivative. Proc Soc Exp Biol Med 196: 164-169.

11) Chan MM. 1995. Inhibition of tumor necrosis factor by curcumin, a phytochemical. Biochem Pharm 49: 15511556.

12) Joe B, Lokesh BR. 1994. Role of capsaicin, curcumin and dietary $n-3$ fatty acids in lowering the generation of reactive oxygen species in rat peritoneal macrophages. Biochim Biophys Acta 1224: 255-263.

13) Ruby AJ, Kuttan G, Babu KD, Rajasekharan KN, Kuttan R. 1995. Anti-tumor and antioxidant activity of natural curcuminoids. Cancer Lett 94: 79-83.

14) Inano $\mathrm{H}$, Onoda $M$, Inafuku $N$, Kubota $M$, Kamada 
Y, Osawa T, Kobayashi H, Wakabayashi K. 1999. Chemoprevention by curcumin during the promotion stage of tumorigenesis of mammary gland in rats irradiated with gamma-rays. Carcinogenesis 20: 1011-1018.

15) Conney AH, Lysz T, Ferraro T, Abidi TF, Manchand PS, Laskin JD, Huang MT. 1991. Inhibitory effect of curcumin and some related dietary compounds on tumor promotion and arachidonic acid metabolism in mouse skin. Adv Enzyme Regul 31: 385-396.

16) Rao TS, Basu N, Siddiqui HH. 1982. Anti-inflammatory activity of curcumin analogues. Indian J Med Res 75: 574-578.

17) Vlietinck AJ, De Bruyne T, Apers S, Pieters LA. 1998. Plant-derived leading compounds for chemotherapy of human immunodeficiency virus (HIV) infection. Planta Med 64: 97-109.

18) Miura K, Nakatani N 1989. Antioxidative activity of flavonoids from thyme (Thymus vulgaris L.). Agric Biol Chem 53: 3043-3045.

19) Kikuzaki H, Nakatani N. 1993. Antioxidant effects of some ginger constituents. J Food Sci 58: 1407-1410.

20) Larson JL, Bull RJ. 1992. Metabolism and lipoperoxidative activity of trichloroacetate and dichloroacetate in rats and mice. Toxicol Appl Pharmacol 115: 268-277.

21) Leighton F, Poole B, Beaufay H, Baudhuin P, Coffey JW, Fowler S, De Duve C. 1968. The large-scale separation of peroxisomes, mitochondria, and lysosomes from the livers of rats injected with triton WR-1339. Improved isolation procedures, automated analysis, biochemical and morphological properties of fractions. J Cell Biol 37: 482-513.

22) Zanelli U, Puccini P, Acerbi D, Ventura P, Gervasi PG. 1996. Induction of peroxisomal $\beta$-oxidation and $\mathrm{P}-450$ $4 \mathrm{~A}$-dependent activities by pivalic and trichloroacetic acid in rat liver and kidney. Arch Toxicol 70: 145-149.

23) Beauchamp C, Fridovich I. 1971. Superoxide dismutase: Improved assays and an assay applicable to acrylamide gels. Anal Biochem 44: 276-287.

24) Beers RF Jr, Sizer IW. 1952. Spectrophotometric method for measuring the breakdown of hydrogen peroxide by catalase. J Biol Chem 195: 133-140.

25) Lawrence RA, Burk RF. 1976. Glutathione peroxidase activity in selenium-deficient rat liver. Biochem Biophys Res Commun 71: 952-958.

26) Pinto RE, Batley W. 1969. The effect of age and sex on glutathione reductase and glutathione peroxidase activities and on aerobic glutathione oxidation in rat liver homogenates. Biochem J 112: 109-115.

27) Kornberg A, Horecker BL. 1955. Glucose-6-phosphate dehydrogenase. Methods Enzymol 1: 323-327.

28) Taniguchi M, Hara T. 1983. Effects of riboflavin and selenium deficiencies on glutathione and its relating enzyme activities with respect to lipid peroxide content of rat liver. J Nutr Sci Vitaminol 29: 283-292.

29) Newton GL, Dorian R, Fahey RC. 1981. Analysis of biological thiols : derivatization with monobromobomane and separation by reverse-phase high-performance liquid chromatography. Anal Biochem 114: 383-387.

30) Lowry OH, Rosebrough NJ, Farr AL, Randall RJ. 1951. Protein measurement with the Folin phenol reagent. $J$ Biol Chem 193: 265-275.

31) Ammon HP, Wahl MA. 1991. Pharmacology of curcuma longa. Planta Med 57: 1-7.

32) Wahlstrom B, Blennow G. 1978. A study on the fate of curcumin in the rat. Acta Pharmacol Toxicol (Copenh) 43: 86-92.

33) Pan MH, Huang TM, Lin JK. 1999. Biotransformation of curcumin through reduction and glucuronidation in mice. Drug Metab Dispos 27: 486-494.

34) Shaw S, Rubin KP, Lieber CS. 1983. Depressed hepatic glutathione and increased diene conjugates in alcoholic liver disease: Evidence of lipid peroxidation. Dig Dis Sci 28: $585-589$.

35) Sai-Kato K, Takagi A, Umemura T, Hasegawa R, Kurokawa Y. 1995. Role of oxidative stress in nongenotoxic carcinogenesis with special reference to liver tumors induced by peroxisome proliferators. Biomed Environ Sci 8: 269-279.

36) Pigeolet E, Corbisier P, Houbion A, Lambert D, Michiels C, Raes M, Zachary MD, Remacle J. 1990. Glutathione peroxidase, superoxide dismutase, and catalase inactivation by peroxidases and oxygen derived free radicals. Mech Ageing Dev 51: 283-297.

37) Elcombe CR. 1985. Species in carcinogenicity and peroxisome proliferation due to trichloroethylene : a biochemical human hazard assessment. Arch Toxicol 8 (Suppl): 6-17.

38) DeAngelo AB, Daniel FB, McMillan L, Wernsing P, Savage RE Jr. 1989. Species and strain sensitivity to the induction of peroxisome proliferation by chloroacetic acids. Toxicol Appl Pharmacol 101: 285-298.

39) Larson JL, Bull RJ. 1992. Species differences in the metabolism of trichloroethylene to the carcinogenic metabolites trichloroacetate and dichloroacetate. Toxicol Appl Pharmacol 11 5: 278-285.

40) Esterbauer H, Dieber-Rotheneder M, Striegl G, Waeg G. 1991. Role of vitamin $\mathrm{E}$ in preventing the oxidation of low-density lipoprotein. Am J Clin Nutr 53 (1 Suppl): 314S-321S.

41) Markus F, Daood HG, Kapitany J, Biacs PA. 1999. Change in the carotenoid and antioxidant content of spice red pepper (paprika) as a function of ripening and some technological factors. J Agric Food Chem 47: 100107.

42) Moon J-H, Terao J. 1998. Antioxidant activity of caffeic acid and dihydrocaffeic acid in lard and human lowdensity lipoprotein. J Agric Food Chem 46: 5062-5065.

43) Tcnnesen HH, Greenhill JV. 1992. Studies on curcumin and curcumanoids. XXII: Curcumin as a reducing agent and as a radical scavenger. Int $J$ Pharmaceutics 87: $79-87$. 